\title{
Gender-Pay Equity in Academic Neurosurgery at United States Public Universities
}

Kathryn N. Kearns ${ }^{1}$, Ching-Jen Chen ${ }^{1}$, John A. Jane ${ }^{2}$, Yashar Kalani ${ }^{3}$, Mark E. Shaffrey ${ }^{2}$, Min S. Park ${ }^{2}$

1. Neurosurgery, University of Virginia School of Medicine, Charlottesville, USA 2. Neurosurgery, University of Virginia, Charlottesville, USA 3. Neurosurgery, Barrow Neurological Institute, Charlottesville, USA

Corresponding author: Min S. Park, mp2tq@hscmail.mcc.virginia.edu

\section{Abstract \\ Background}

Compensation has historically been unequal for men versus women in medical fields, particularly in surgical subspecialties.

\section{Objective}

We analyzed associations between gender and compensation and identified factors associated with compensation among male and female academic neurosurgeons in the United States (US) public institutions.

\section{Methods}

This is a cross-sectional study of available data for the 2016-2017 fiscal years associated with male and female neurosurgical faculty from public, academic institutions within the US. The data used for analysis included total annual salary, which consisted of the base salary and additional compensation. Other gleaned data included faculty demographics, training, and academic appointments. The male and female neurosurgeons' data were separated into two respective gender groups and then were compared. Predictors of compensation were identified using univariable and non-imputed and multiply-imputed multivariable statistical models.

\section{Results}

The cohort was comprised of 460 neurosurgery faculty members (female $n=34$; male $n=426$ ). Total annual salaries were comparable between the genders. Females were more likely to be younger $(\mathrm{p}=0.001)$, to have completed neurosurgery training recently $(\mathrm{p}=0.003)$, to have had fellowship training $(\mathrm{p}=0.011)$, and to have lower $\mathrm{h}$-indices $(\mathrm{p}=0.003)$ compared to males. Males and females differed in academic ranks $(\mathrm{p}=0.035)$ and neurosurgical subspecialties $(p=0.038)$. Midwest $(a \beta)=-$ US $\$ 337,516.7, p=0.002)$, South $(a \beta=-U S \$ 302,500.5$, $\mathrm{p}=0.003$ ), and West $(\mathrm{a} \beta=-\mathrm{US} \$ 276,848.8, \mathrm{p}=0.005$ ) practices were independent predictors of lower annual

Received 05/28/2020

Review began 06/06/2020 Review ended 06/11/2020 Published 06/16/2020

\section{() Copyright 2020}

Kearns et al. This is an open access article distributed under the terms of the Creative Commons Attribution License CC-BY 4.0., which permits unrestricted use, distribution, and reproduction in any medium, provided the original author and source are credited. compensation. Chair position $(\mathrm{a} \beta=\mathrm{US} \$ 174,180.3, \mathrm{p}=0.019)$ and associate professorship $(\mathrm{a} \beta=\mathrm{US} \$ 126,633.4$, $\mathrm{p}=0.037$ ) were independent predictors of higher annual compensation. Gender was not a significant predictor of total annual compensation.

\section{Conclusions}

Total salaries were not different between male and female neurosurgeons in public, academic institutions in the US. Gender was not a significant predictor of total annual compensation. This study is applicable to public institutions in states with Freedom of Information Act reporting requirements.

Categories: Medical Education, Miscellaneous, Neurosurgery

Keywords: academic neurosurgery, compensation, gender, equity, public

\section{Introduction}

Female representation in the field of medicine has grown substantially over the past few decades with women now representing $50 \%$ of medical school matriculants - a stark increase from the less than $10 \%$ reported previously $[1,2]$. While this trend is undoubtedly encouraging, female representation remains poor in the historically male-dominated surgical specialties, which include cardiothoracic surgery, orthopedic surgery, and neurological surgery [3,4]. Even in the larger category of science, technology, engineering, and mathematics (STEM) professions, women comprise approximately $48 \%$ of the workforce [5]. Studies have observed lower rates of female representation in professions with demanding schedules and competitive environments, such as those commonly experienced in STEM fields [1,4-7]. Lack of female mentors and role models has also been reported by women as deterrents in entering these professions $[1,2,4,7,8]$. Potential gender-related salary differences in these fields may act as additional disincentives for women [7]. We sought to investigate any potential association between gender and annual compensation and to identify 
other factors associated with annual compensation among male and female neurosurgeons from public institutions across the United States (US).

\section{Materials And Methods \\ Study cohort selection}

This is a cross-sectional study of publicly available data for the 2016 and 2017 fiscal years from the American Association of Neurological Surgeons (AANS) Neurosurgical Residency Training Program Directory (https://www.aans.org/Trainees/Residency-Directory). The following inclusion criteria were devised: (1) neurological surgery faculties from public, academic institutions within the US; and (2) institutions with publicly-accessible data from state-run databases in accordance with the Freedom of Information Act [9].

The AANS Neurosurgical Residency Training Program Directory described above was then screened for residency training programs at public institutions in states with Freedom of Information act reporting requirements [10]. Programs were selected for inclusion if they had published salaries to review so as to verify that their data was complete. Additional subject information was gathered based on available data published on individual program websites. Faculty from private or foreign institutions as well as those from fellowship-only programs were excluded from the analysis.

\section{Data collection}

Data for analysis was obtained via Internet search in July 2018. Extracted data included faculty demographics, training, and appointment variables. Faculty demographic variables comprised faculty age, gender, and geographic region of practice, the latter of which was categorized into (1) East (Maryland, New Jersey, and New York); (2) Midwest (Illinois, Iowa, Michigan, Minnesota, Missouri, Nebraska, Ohio, Oklahoma, and Wisconsin); (3) North (Vermont); (4) South (Florida, Georgia, Kentucky, Mississippi, North Carolina, Texas, Virginia, and West Virginia); and (5) West (Arizona, California, New Mexico, Utah, and Washington) as decided by the authors. Training variables consisted of time since training completion (residency or fellowship), any advanced degree(s) (in addition to doctor of medicine [M.D.], i.e. doctor of philosophy [Ph.D.]), and any fellowship training. Faculty appointment variables included academic rank (assistant professor, associate professor, or professor), specialty within neurological surgery, chair position, residency program director position, and h-index (via Scopus) [11]. The total annual compensation (reported in US dollars [US\$]), which included basic salary and any additional compensation, was used in the analysis. Faculty with incomplete compensation information were designated as missing. To account for varying compensation sources, in which all programs may not be required to report total compensation, a salary of $\$ 211,326$ was identified, representing 1/2 standard deviation below the mean, and was used as the threshold for inclusion. Programs with faculty salaries below this threshold were designated as having incomplete data. Due to the public availability of the data, institutional review board (IRB) approval and consent were not necessary.

\section{Statistical analysis}

All statistical analyses were performed using Stata, version 14.2 (StataCorp LP, College Station, TX). Differences in demographics, training, academic position, specialty, and compensation were compared between male and female neurosurgeons. Continuous variables were compared using Student's $t$ or MannWhitney $U$ tests, as appropriate. Categorical variables were compared using Pearson's $\chi^{2}$ or Fisher's exact tests, as appropriate. Linear regression analyses were performed to identify univariable predictors of annual compensation. Univariable predictors of annual compensation with $\mathrm{p}<0.10$ were then entered as independent variables into a multivariable linear regression model to identify independent predictors of annual compensation (model 1). To avoid list-wise deletions due to missing data in the multivariable linear regression model, multiple imputation by chained equations with $\mathrm{m}=50$ was performed. Imputed values for academic rank (3.9\%), h-index (3.9\%), years out from training (2\%), and annual compensation (58.9\%) were generated using conditional regression models with the following auxiliary variables: sex, geographic region, chair position, residency program director position, and advanced degree(s). Parameter estimates from analyzing the imputed datasets were pooled according to Rubin's rules (model 2) [12]. Statistical significance was defined as $\mathrm{p}<0.05$, and all tests were two-tailed.

\section{Results}

Of 1696 neurosurgeons from the 132 American AANS neurosurgery residency programs, 460 faculty members from 39 institutions were included in the study for analysis. The study cohort compares the faculty demographics, training, and appointment variables between female $(n=34)$ and male $(n=426)$ neurosurgeons (Table 1). Female neurosurgeons were more likely to be younger (mean 45.8 vs. 53.8 years, $\mathrm{p}=0.001$ ), to have had completed training recently (mean 11 vs. 17.7 years, $\mathrm{p}=0.003)$, to have had fellowship training (97.1\% vs. $79 \%, \mathrm{p}=0.011$ ), and to have lower h-indices (mean 11.2 vs. $19.5, \mathrm{p}=0.003$ ) compared to male neurosurgeons. Women completed fellowships primarily in pediatric neurosurgery (13/34), spine (7/34), or neurooncology (6/34). Distributions of academic rank $(\mathrm{p}=0.035)$ and specialty $(\mathrm{p}=0.038)$ were also different between female and male neurosurgeons, with males holding more full professorships, and completing more vascular neurosurgery, functional/stereotactic/radiosurgery, and spine fellowships than their female 


\section{Cureus}

colleagues. Geographic region of practice, advanced degree, chair position, residency program director position, and trauma/critical care specialization were comparable between female and male neurosurgeons. Total annual salaries were also similar between female and male neurosurgeons (mean US $\$ 534,400$ vs. US\$602,300, $p=0.430$ ).

\begin{tabular}{|c|c|c|c|c|}
\hline & Total $(n=460)$ & Female $(n=34)$ & Male $(n=426)$ & $\begin{array}{l}\mathrm{p}- \\
\text { value }\end{array}$ \\
\hline Age, yrs (SD) & $53.2(12)$ & $45.8(8.1)$ & $53.8(12)$ & 0.001 \\
\hline $\begin{array}{l}\text { Geographic region, } n(\%) \text {; Regional gender } \\
\text { distribution }\end{array}$ & & & & 0.617 \\
\hline East & $39 / 460(8.5)$ & 2/34 (5.9); 2/39 (5.1) & $37 / 426$ (8.7); 37/39 (94.9) & \\
\hline Mildwest & $\begin{array}{l}113 / 460 \\
(24.6)\end{array}$ & $\begin{array}{l}\text { 10/34 (29.4); 10/113 } \\
(8.8)\end{array}$ & $\begin{array}{l}\text { 103/426 (24.2); 103/113 } \\
(91.2)\end{array}$ & \\
\hline North & $5 / 460(1.1)$ & 1/34 (2.9); 1/5 (20.0) & 4/426 (0.9); 4/5 (80.0) & \\
\hline South & $\begin{array}{l}153 / 460 \\
(33.3)\end{array}$ & $\begin{array}{l}11 / 34(32.4) ; 11 / 153 \\
(7.2)\end{array}$ & $\begin{array}{l}\text { 142/426 (33.3); 142/153 } \\
(92.8)\end{array}$ & \\
\hline West & $\begin{array}{l}150 / 460 \\
(32.6)\end{array}$ & $\begin{array}{l}\text { 10/34 (29.4); 10/150 } \\
(6.7)\end{array}$ & $\begin{array}{l}\text { 140/426 (32.9); 140/150 } \\
(93.3)\end{array}$ & \\
\hline Years out from training, yrs (SD) & $17.2(12.3)$ & $11(8)$ & $17.7(12.5)$ & 0.003 \\
\hline Advanced degree(s), n (\%) & 90/460 (19.6) & 5/34 (14.7) & $85 / 426(20)$ & 0.458 \\
\hline Academic rank, $\mathrm{n}(\%)$ & & & & 0.035 \\
\hline Assistant professor & $\begin{array}{l}158 / 442 \\
(35.7)\end{array}$ & $17 / 32(53.1)$ & $141 / 410(34.4)$ & \\
\hline Associate professor & $\begin{array}{l}111 / 442 \\
(25.1)\end{array}$ & 9/32 (28.1) & $102 / 410(24.9)$ & \\
\hline Professor & $\begin{array}{l}173 / 442 \\
(39.1)\end{array}$ & $6 / 32(18.8)$ & $16 / / 410(40.7)$ & \\
\hline Specialty, n (\%) & & & & 0.038 \\
\hline Neuro-oncology & $66 / 415(15.9)$ & 6/34 (17.7) & 60/381 (15.7) & \\
\hline Vascular Neurosurgery & $94 / 415(22.7)$ & 3/34 (8.8) & $91 / 381(23.9)$ & \\
\hline Pediatric Neurosurgery & 76/415 (18.3) & 13/34 (38.2) & 63/381 (16.5) & \\
\hline Functional/ Stereotactıc /Radıosurgery & $61 / 415(14)$. & 4/34 (11.8) & $5 / / 381(15)$ & \\
\hline Spine & $\begin{array}{l}109 / 415 \\
(26.3)\end{array}$ & $7 / 34(20.6)$ & $102 / 381(26.8)$ & \\
\hline Trauma/Critical Care & 9/415 (2.2) & $1 / 34(2.9)$ & $8 / 381(2.1)$ & \\
\hline Fellowship training, n (\%) & $\begin{array}{l}367 / 457 \\
(80.3)\end{array}$ & 33/34 (97.1) & $334 / 423(79)$ & 0.011 \\
\hline Chair position, n (\%) & $40 / 460(8.7)$ & $3 / 34(8.8)$ & $37 / 426(8.7)$ & 1.000 \\
\hline Residency program director position, $\mathrm{n}(\%)$ & $36 / 460(7.8)$ & $1 / 34(2.9)$ & $35 / 426(8.2)$ & 0.502 \\
\hline n-Index (SD) & $18.9(15.4)$ & $11.2(11.9)$ & $19.5(15.5)$ & 0.003 \\
\hline Annual salary, US\$1,000 (SD) & $597.3(308.5)$ & $534.4(225.3)$ & $602.3(314.1)$ & 0.430 \\
\hline
\end{tabular}


We also examined for predictors of total annual compensation in univariable and multivariable models (Table 2). In the univariable model, geographic location of practice in the Midwest ( $\beta=-$ US $\$ 387,382$ [$581,256.6--193,508.1], p<0.001)$, South $(\beta=-$ US $\$ 332,090.2[-510,586.8--153,593.7], p<0.001)$, and West $(\beta=-$ US $\$ 271,852.2$ [-444.157.8--96,546.5], $\mathrm{p}=0.003$ ) were associated with lower total annual compensation compared to practice in the East. Longer time interval since training completion ( $\beta=\mathrm{US} \$ 5,393.3$ /year $[1,238.5-9,548.1], \mathrm{p}=0.011$ ), chair position ( $\beta=\mathrm{US} \$ 239,517.8$ [239,517.8], $\mathrm{p}<0.001$ ), and higher $\mathrm{h}$-indices ( $\beta=U S \$ 6,689.9[3,803.2-9,576.6], p<0.001)$ were associated with higher total annual compensation. Academic ranks of associate professor ( $\beta=$ US $\$ 135,683.8[25,767-245,600.5], \mathrm{p}=0.016)$ and professor (

$\beta=$ US $\$ 234,165.7[133,788.7-334,542.7], p<0.001$ ) were also associated with higher total annual compensation compared to assistant professor. Faculty age and gender were not associated with total annual compensation.

\begin{tabular}{|c|c|c|c|c|c|c|c|c|c|}
\hline \multirow[b]{2}{*}{ Variables } & \multicolumn{3}{|l|}{ Univariable } & \multicolumn{3}{|c|}{ Model 1 (n=178) } & \multicolumn{3}{|c|}{ Model $2(n=460)^{\star}$} \\
\hline & bcoefficient & $95 \% \mathrm{Cl}$ & $\begin{array}{l}\mathrm{p}- \\
\text { value }\end{array}$ & bcoefficient & $95 \% \mathrm{Cl}$ & $\begin{array}{l}\mathrm{p} \text { - } \\
\text { value }\end{array}$ & bcoefficient & $95 \% \mathrm{Cl}$ & $\begin{array}{l}\mathrm{p} \text { - } \\
\text { value }\end{array}$ \\
\hline Age & 3,820 & $-878.4-8,518.4$ & 0.110 & - & - & - & - & - & - \\
\hline Male & $67,883.8$ & $\begin{array}{l}-101,302.7- \\
237,070.2\end{array}$ & 0.430 & - & - & - & - & - & - \\
\hline \multicolumn{10}{|l|}{ Geographic region } \\
\hline East & Ref & Ref & Ref & Ref & Ref & Ref & Ref & Ref & Ref \\
\hline Midwest & $-387,382$ & $\begin{array}{l}-581,256.6-- \\
193,508.1\end{array}$ & $<0.001$ & $-356,224.1$ & $\begin{array}{l}-549,243.1- \\
163,205.1\end{array}$ & $<0.001$ & $-337,516.7$ & $\begin{array}{l}-545,025.5-- \\
130,008\end{array}$ & 0.002 \\
\hline North & - & - & - & - & - & - & $35,951.2$ & $\begin{array}{l}-329,628.2- \\
401,530.6\end{array}$ & 0.846 \\
\hline South & $-332,090.2$ & $\begin{array}{l}-510,586.8- \\
153,593.7\end{array}$ & $<0.001$ & $-312,617.8$ & $\begin{array}{l}-492,200.8- \\
133,034.7\end{array}$ & 0.001 & $-302,500.5$ & $\begin{array}{l}-499,106.4-- \\
105,894.6\end{array}$ & 0.003 \\
\hline West & $-271,852.2$ & $\begin{array}{l}-444.157 .8-- \\
96,546.5\end{array}$ & 0.003 & $-284,049.7$ & $\begin{array}{l}-455,562.9- \\
112,536.5\end{array}$ & 0.001 & $-276,848.8$ & $-467,804.6-85,893$ & 0.005 \\
\hline Years out from training & $5,393.3$ & $1,238.5-9,548.1$ & 0.011 & $-3,812.2$ & $-9,344.4-1,720$ & 0.176 & $-3,175.2$ & $-8,702.9-2,352.5$ & 0.254 \\
\hline Advanced degree(s) & $20,613.6$ & $\begin{array}{l}-91,201.1- \\
132,428.2\end{array}$ & 0.717 & - & - & - & - & - & - \\
\hline \multicolumn{10}{|l|}{ Academic rank } \\
\hline Assistant professor & Ref & Ref & Ref & Ref & Ref & Ref & Ref & Ref & Ref \\
\hline Associate professor & $135,683.8$ & $25,767-245,600.5$ & 0.016 & 137,105 & $18,771.8-255,438.2$ & 0.023 & $126,633.4$ & $7,547-245,719.8$ & 0.037 \\
\hline Professor & $234,165.7$ & $\begin{array}{l}133,788.7- \\
334,542.7\end{array}$ & $<0.001$ & 145,088 & $\begin{array}{l}-12,251.9- \\
302,427.9\end{array}$ & 0.070 & $135,166.3$ & $-21,041-291,374$ & 0.089 \\
\hline \multicolumn{10}{|l|}{ Specialty, n (\%) } \\
\hline Neuro-oncology & Ref & Ref & Ref & - & - & - & - & - & - \\
\hline Vascular Neurosurgery & $-52,049.6$ & $\begin{array}{l}-203,212.8- \\
99,113.6\end{array}$ & 0.498 & - & - & - & - & - & - \\
\hline Pediatric Neurosurgery & $-109,987.2$ & $\begin{array}{l}-255,555.8- \\
35,581.5\end{array}$ & 0.138 & - & - & - & - & - & - \\
\hline $\begin{array}{l}\text { Functional/ Stereotactic } \\
\text { /Radiosurgery }\end{array}$ & $-108,904.4$ & $\begin{array}{l}-269,275.5- \\
51,466.7\end{array}$ & 0.182 & - & - & - & - & - & - \\
\hline Spine & $113,172.5$ & $-25,820-252,164.9$ & 0.110 & - & - & - & - & - & - \\
\hline Trauma/Critical Care & $84,569.3$ & $\begin{array}{l}-533,026.3- \\
702,164.9\end{array}$ & 0.787 & - & - & - & - & - & - \\
\hline Fellowship training & $30,273.6$ & $\begin{array}{l}-92,793.7- \\
153,340.9\end{array}$ & 0.628 & - & - & - & - & - & - \\
\hline
\end{tabular}




\section{Cureus}



In the non-imputed and imputed multivariable models, geographic location of practice in the Midwest (nonimputed a $\beta=-U S \$ 356,224.1[-549,243.1--163,205.1], p<0.001$; imputed a $\beta=-U S \$ 337,516.7[-545,025.5--$ $130,008], p=0.002$ ), South (non-imputed $a \beta=-U S \$ 312,617.8[-492,200.8--133,034.7], p=0.001$; imputed a $\beta=-$ US $\$ 302,500.5[-499,106.4--105,894.6], p=0.003)$, and West (non-imputed a $\beta=-U S \$ 284,049.7[-455,562.9--$ $112,536.5], p=0.001$; imputed $\mathrm{a} \beta=-\mathrm{US} \$ 276,848.8[-467,804.6-85,893], \mathrm{p}=0.005$ ) remained significant predictors of lower total annual compensation compared to practice in the East. Chair position also remained a significant predictor of higher total annual compensation in the non-imputed $(a \beta=U S \$ 169,151.3$ [32,323.7-305,978.9], $\mathrm{p}=0.016)$ and imputed $(\mathrm{a} \beta=\mathrm{US} \$ 174,180.3$ [29,794.3-318,566.3], $\mathrm{p}=0.019)$ models. Time interval since training completion and $\mathrm{h}$-index were no longer significant predictors of higher total annual compensation in the multivariable models. Associate professor rank was associated with higher total annual compensation compared to assistant professor rank in the non-imputed $(\mathrm{a} \beta=\mathrm{US} \$ 137,105[18,771.8$ $255,438.2], \mathrm{p}=0.023$ ) and imputed ( $\mathrm{\beta}=\mathrm{US} \$ 126,633.4$ [7,547-245,719.8], $\mathrm{p}=0.037$ ) models. However, professor rank was not associated with higher total annual compensation compared to assistant professor rank.

\section{Discussion}

While women constituted approximately $47 \%$ of the entire workforce in the US in 2015 , they only accounted for $24 \%$ of employees within the STEM fields [13]. In a 2017 study of female representation in the STEM fields, Kahn and Ginther observed an overall salary gap of $17 \%$ between male and female Ph.D. holders [14]. Part of this difference can be attributed to the greater participation of men in more lucrative specialties, such as engineering and mathematics, while women with STEM degrees tend to enter the lower-paying fields of physical and life sciences. Despite greater female representation in the physical and life sciences workforce, an $8 \%$ general wage gap and a $9 \%$ wage gap within upper-level management in these disciplines still persisted between genders [8]. Broyles et al. compared the average earnings between male and female chemists, and observed a total pay gap of $26 \%, 17 \%$ of which was found to be due solely to employer discrimination [5]. This resulted in female chemists earning US $\$ 3,070$ less annually than men after accounting for potential contributing factors (education, experience, etc) [5]. Interestingly, the wage gap is smaller in the male-dominated field of engineering, with female engineers earning approximately $7 \%$ less per hour than their male counterparts [8].

This trend continued into the realm of medicine as well. Within the discipline as a whole, women represented $25 \%$ of all practicing physicians and $34 \%$ of full-time medical school faculty members [2]. Jena et al. reported gender differences in compensation at all levels of faculty rank among academic physicians, and found that the annual adjusted salaries of female full professors (US\$250,971) were comparable to those of male associate professors (US\$247,212), while male full professors earned US $\$ 33,620$ more than female full professors annually [4]. In surgical subspecialties, women earned US\$43,728 less per year than men in the same fields [4]. After adjusting for age, experience, specialty, faculty rank, research productivity, and payments by Medicare, they concluded that the annual salaries of women in academic medicine were $8 \%$ lower than those of men, resulting in an unexplained annual discrepancy of US\$19,879 [4]. Similarly, Weiss et al. found that women were paid US $\$ 50,000$ less overall than men when comparing unadjusted annual industry payments to male and female physicians. This gap widened to US\$70,000 among surgeons [15]. Surgical subspecialties showed the greatest gender differences in absolute adjusted annual compensation, with men earning US $\$ 43,728$ more than women with the same qualifications [4]. This difference was most pronounced in the historically male dominated subspecialties, such as orthopedic surgery (absolute difference of US\$40,953), hematology/oncology (absolute difference of US\$37,793), and surgical obstetrics/gynecology (absolute difference of US\$36,390) [4].

There are also identifiable publication biases between men and women that may contribute to general compensation disparity [16]. According to a recent study analyzing the gender gap in academic literature, women are less likely to obtain senior authorships, less frequently publish as first authors in prestigious journals such as Nature, Lancet, BMJ, and the New England Journal of Medicine, and are less likely to be invited to submit articles when compared to their male colleagues [17]. These publication biases may contribute to the lack of women achieving full professorships in academic neurosurgery programs. 
Reduced rates of compensation for women were often attributed to the idea that women provide less "human capital," or productive labor, than men [5]. Women were more likely to take maternity leave or work part-time and were less likely to negotiate for themselves [1,7]. Furthermore, men have been found to be more motivated by monetary compensation when compared to women, who are more likely to be motivated by predictable schedules and flexible hours [6]. While these differences mitigated some of the gender pay gap, approximately $17 \%$ of the gap across all STEM fields was attributed to employer discrimination or immeasurable factors [5]. Therefore, no identifiable statistically significant gender disparity in compensation for academic neurosurgeons at public universities in the US as found in the present paper is a rather unique finding.

In addition to our reported gender-pay equity, several aspects of the field of neurosurgery appear to be unique when compared to other surgical subspecialties. Despite having one of the longest and most rigorous training periods, neurosurgery residents consistently have lower rates of burnout and higher personal accomplishment scores than residents and fellows of other specialties [18-21]. When compared with residents of 13 other surgical specialties, neurosurgery residents ranked 12/14 in rates of depression, 12/14 in rates of low mental quality of life, 13/14 in rates of work/home conflict, and 8/14 in overall rates of burnout [19]. Further examination of burnout among neurosurgery residents revealed statistically significant lower rates of components of this syndrome including emotional exhaustion, feelings of depersonalization, and burnout when compared to a control group of residents and fellows from other specialties [20]. Interestingly, there was no statistically significant difference between these results when comparing neurosurgery residents by gender, while differences were reported for general surgery residents [20]. The question must then be asked: what is different about neurosurgeons?

A recent survey- based study examining grit (defined as continued fortitude in the face of hardship) and resilience (ability to recovery from a setback) and their relationship to burnout in neurosurgery residents reported an inverse relationship between self-reported grit/resilience and burnout [18]. When evaluating this conclusion with the lower reported rates of burnout in neurosurgery residents, it can be determined that neurosurgery residents possess, if subjectively, at least a statistically higher level of perseverance and fortitude when compared to other medical specialty physicians. Perhaps this can be explained by the intense rigor of the neurosurgical residency matching and training processes. It is no secret that neurosurgery has one of the most competitive residency application processes and applicants must necessarily be intensely committed to the field. Therefore, both male and female applicants must have a rather basic understanding of the expected workload before committing. It has also been proposed that the high sense of personal accomplishment reported by neurosurgical residents may be due to the increased amount of time spent caring for acutely ill patients that make significant recovery after surgical interventions [20]. While residents of other surgical subspecialties may not see such profound improvement in clinical status as a direct result of their care, neurosurgery residents undoubtedly have a sense of personal influence in their training. Therefore, the gender-pay difference may not solely be a result of the women in the field, but rather of the general type of person drawn to the field: strong, resilient physicians with a deep passion for their work, who recognize that strength in others.

Regardless, a great deal of credit must be given to the pioneering women who first made their place in the field of neurosurgery and have worked to promote further female participation. We must also consider the greater societal movement away from the "traditional family" where women are expected to stay home. More and more, women are motivated, either internally or externally, to pursue professions previously deemed inappropriate, and "career women" are growing in number and following the example of those first few. The number of women pursuing a career in neurosurgery has been steadily growing. In $2016,17 \%$ of applicants that matched into neurosurgery residencies were women, an increase from 14\% in 2014 [22]. Additionally, the desirability of an academic practice may be similar between men and women. Renfrow et al. analyzed 379 female neurosurgery residency graduates from 1964 to 2013 and found that 26\% elected to have an academic practice, a percentage comparable to the overall percentage of board-certified neurosurgeons that entered academic medicine (33\%) [2,22]. Historically, women have not entered academic neurosurgery or neurosurgery in general, but current trends indicate that more women are entering the field. From this female cohort, $46.2 \%$ achieved the rank of assistant professor, $36.3 \%$ achieved associate professorship, and $17.6 \%$ became full professors [2]. Our study revealed similar rates of professorship with $53.1 \%, 28.1 \%$, and $18.8 \%$ of female academic neurosurgeons achieving assistant, associate, and full professorships, respectively. However, the distributions of academic ranks were still different between male and female neurosurgeons ( $\mathrm{p}=0.035$ ), with $34.4 \%$ of male neurosurgeons holding assistant professorships, $24.9 \%$, associate professorships, and $40.7 \%$, full professorships.

National rates of female participation in leadership positions are increasing substantially. As of 2016, more women are holding higher positions, such as neurosurgery department chair, vice-chair, and director positions, and women have exhibited increased participation in national organizations such as the AANS and Council of State Neurosurgical Societies (CSNS) [2]. In fact, women constituted 19.3\% of the 2016/2017 AANS Board of Directors, which was recently led by the first female AANS president [2]. While a lack of female mentors and role models was often identified as an explanation for lower rates of women in surgical specialties, the increasing number of women in neurosurgical leadership roles may be contributing to the compensation parity reported in this study and may be one factor in the rising rate of female participation in neurosurgery as a whole $[1,2,4,7,8]$. Additionally, organizations such as Women in Neurosurgery have made 
it their mission to increase visibility and availability of mentorship for aspiring female medical students and residents. Because most of the identified differences in our study directly stem from temporal experience (age, time since training completion, and h-index) rather than gender, it is not unreasonable to expect that, as more women enter the field of academic neurosurgery and assume leadership positions, even the unadjusted annual salaries will begin to equalize.

This data was presented as an abstract at the AANS Scientific Meeting. (Abstract: Kearns K, Chen CJ, Kalani Y, Shaffrey M, Park M. Gender-Pay Equity in Academic Neurosurgery at United States Public Universities. American Association of Neurological Surgeons (AANS) Annual Scientific Meeting; 2019)

https://www.aans.org/Annual-Scientific-Meeting/2019/Online-Program/Eposter? eventid=48888\&itemid=PLENARY_III\&propid $=45035$

\section{Limitations}

One significant limitation surrounding this study is the scarcity of available data for academic neurosurgeons and their salaries. This study only analyzes data made publicly available by programs in states adopting the Freedom of Information act. The programs in this study were selected for inclusion based on completed annual compensation data published on these platforms. The collected data was dependent upon full disclosure of the reporting institutions and may have been subjected to reporting bias. Given that sufficient compensation data was only available for 460 of the 1696 neurosurgeons at AANS-accredited programs, there is a question of the generalizability of our findings to the neurosurgical community at large. It is possible that, if data were to be obtained from private programs or those programs that currently have incomplete public salary reports, a gender-compensation disparity might be identified, as has been shown in similar surgical subspecialties. It has certainly been shown that neurosurgeons in private practice make significantly more in annual salary than do academic neurosurgeons [23]. However, the proportions of female neurosurgeons who pursue academic versus private practices are comparable to those of male neurosurgeons, suggesting the possibility of similar compensation equity in private realms as well [2]. Additionally, if a pay difference were to be identified, it would not detract from the encouraging trends showing increased female participation in academic neurosurgery, or indeed in the field of neurosurgery as a whole. Future studies in this vein would certainly benefit from more complete access to salary reporting measures used by individual programs.

Perhaps the greatest limitation of this study was the low representation of women in our database. Women constituted approximately $7 \%$ of our total data set, reducing the power of our statistical analysis. The general difficulties with acquiring complete compensation information mentioned above were magnified in the much smaller female cohort and potentially influenced our analysis and conclusion. However, the challenge of missing data was distributed randomly among gender, with an increased predilection for men, given the overwhelming majority of the male cohort.

We assumed that the most recently published information accurately depicted the current state of each program and individual physician characteristics. We acknowledge that such sources often do not contain the most up-to-date information, which may introduce unmeasured biases in our results. There may also be additional salaries paid to faculty that were not reported in the database and, thus, were left unaccounted. Thus, we set a salary threshold for inclusion in our study to mitigate this factor. Each institution likely has different reimbursement strategies for their clinical faculty. Programs may elect to further compensate faculty with additional responsibilities within the department or institution or those with more clinical and/or academic productivity. This information may be unavailable to those outside of each program.

We included an imputed multivariable model in our analysis to account for missing salary data within the database and to adjust for potential biases due to this missing data. Although multiple imputation minimizes bias and maximizes the use of available data, these fall under the assumption that the data is missing at random. Lastly, the results of this study are limited to clinical neurosurgical faculty in public, academic institutions, which represent a small subset of neurosurgeons within the US. Additionally, some of the programs included in this analysis did not contain any female faculty members. Thus, our results may not be generalizable to the entire neurosurgical community.

\section{Conclusions}

We did not identify a statistically significant difference in annual compensation among female and male academic neurosurgeons in the US practicing at public universities subject to the Freedom of Information Act. Female neurosurgeons were more likely to be younger, to have had completed training recently, to have had fellowship training, and to have lower h-indices. Additionally, male and female neurosurgeons differed in academic ranks and specialties. Geography, academic rank, and the position of department chair were independent predictors of compensation differences. The results of this study suggest that the previously identified gender-compensation discrepancies in similar fields may not be as significant in academic neurosurgery.

\section{Additional Information}




\section{Disclosures}

Human subjects: All authors have confirmed that this study did not involve human participants or tissue. Animal subjects: All authors have confirmed that this study did not involve animal subjects or tissue. Conflicts of interest: In compliance with the ICMJE uniform disclosure form, all authors declare the following: Payment/services info: All authors have declared that no financial support was received from any organization for the submitted work. Financial relationships: All authors have declared that they have no financial relationships at present or within the previous three years with any organizations that might have an interest in the submitted work. Other relationships: All authors have declared that there are no other relationships or activities that could appear to have influenced the submitted work.

\section{References}

1. Thibault GE: Women in academic medicine. Acad Med. 2016, 91:1045-1046. 10.1097/ACM.0000000000001273

2. Renfrow JJ, Rodriguez A, Wilson TA, Germano IM, Abosch A, Wolfe SQ: Tracking career paths of women in neurosurgery. Neurosurgery. 2018, 82:576-582. 10.1093/neuros/nyx251

3. Jagsi R, Griffith KA, Stewart A, Sambuco D, DeCastro R, Ubel PA: Gender differences in the salaries of physician researchers. J Am Med Assoc. 2012, 307:2410-2417. 10.1001/jama.2012.6183

4. Jena AB, Olenski AR, Blumenthal DM: Sex differences in physician salary in US public medical schools . JAMA Intern Med. 2016, 176:1294-1304. 10.1001/jamainternmed.2016.3284

5. How many women work in STEM? . (2020). Accessed: June 11, 2020: https://ilostat.ilo.org/2020/02/11/howmany-women-work-in-stem/.

6. Hoff TJ: Doing the same and earning less: male and female physicians in a new medical specialty . Inquiry. 2004, 41:301-315. 10.1177/004695800404100307

7. de Costa J, Chen-Xu J, Bentounsi Z, Vervoot D: Women in surgery: challenges and opportunities . Int J Surg Glob Heal. 2018, 1:e02. 10.1097/GH9.0000000000000002

8. Women in STEM: a gender gap to innovation . (2011). Accessed: June 11, 2020: http://10.2139/ssrn.1964782.

9. Freedom of Information Act, 5 U.S.C. § 552 . Accessed: July 1, 2019: https://www.justice.gov/oip/freedominformation-act-5-usc-552.

10. State Freedom of Information Laws. (2019). Accessed: June 11, 2020: https://www.nfoic.org/coalitions/state-foi-resources/state-freedom-of-information-laws .

11. Scopus. (2018). Accessed: 23 July, 2019: https://www.scopus.com/freelookup/form/author.uri? zone=\&origin $=$ NO ORIGIN DEFINED.

12. Rubin DB: Multiple Imputation for Nonresponse in Surveys. John Wiley \& Sons, Hoboken, New Jersey; 1987. $10.1002 / 9780470316696$

13. Women in STEM: 2017 update. (2017). Accessed: July 1, 2019: https://www.spglobal.com/_media/documents/women-in-stem-2017-update.pdf.

14. Kahn S, Ginther D: Women and STEM. NBER. 2017, 1-42.

15. Weiss A, Parina R, Tapia VJ, et al.: Assessing the domino effect: female physician industry payments fall short, parallel gender inequalities in medicine. Am J Surg. 2018, 216:723-729. 10.1016/j.amjsurg.2018.07.031

16. Woodrow SI, Gilmer-Hill H, Rutka JT: The neurosurgical workforce in North America: a critical review of gender issues. Neurosurgery. 2006, 59:749-758. 10.1227/01.NEU.0000232671.44297.DF

17. Holman L, Stuart-Fox D, Hauser CE: The gender gap in science: how long until women are equally represented?. PLoS Biol. 2018, 16: e2004956. 10.1371/journal.pbio.2004956

18. Shakir HJ, Cappuzzo JM, Shallwani H, et al.: Relationship of grit and resilience to burnout among U.S. neurosurgery residents. World Neurosurg. 2020, 134:e224-e236. 10.1016/j.wneu.2019.10.043

19. Balch CM, Shanafelt TD, Sloan JA, Satele DV, Freischlag JA: Distress and career satisfaction among 14 surgical specialties, comparing academic and private practice settings. in. Ann Surg. 2011, 254:558-568. 10.1097/SLA.0b013e318230097e

20. Shakir HJ, McPheeters MJ, Shallwani H, Pittari JE, Reynolds RM: The prevalence of burnout among US neurosurgery residents. Neurosurgery. 2018, 83:582-590. 10.1093/neuros/nyx494

21. Dimou FM, Eckelbarger D, Riall TS: Surgeon burnout: a systematic review. J Am Coll Surg. 2016, 222:12301239. 10.1016/j.jamcollsurg.2016.03.022

22. Renfrow JJ, Rodriguez A, Liu A, et al.: Positive trends in neurosurgery enrollment and attrition: analysis of the 2000-2009 female neurosurgery resident cohort. J Neurosurg. 2016, 124:834-839. 10.3171/2015.3.JNS142313

23. Baimas-George M, Fleischer B, Korndorffer JR, Slakey D, DuCoin C: The economics of private practice versus academia in surgery. J Surg Educ. 2018, 75:1276-1280. 10.1016/j.jsurg.2018.03.006 